\title{
DOCUMENTOS DEL TEATRO ALBACETEÑO EN EL SIGLO XVI
}

Emilia Cortés Ibáñez

Los documentos que aquí traemos son una prueba de la actividad teatral existente, durante el siglo XVI, en una villa típicamente agrícola y ganadera.

El primero de ellos está fechado en 1568, el mismo año en que, según Crawford $^{1}$ y Shergold ${ }^{2}$, se representó el Auto de Martyrio de Sant Justo y Pastor, en la Universidad de Alcalá. Los otros dos documentos son de 1571; ambos con la misma fecha: «dies y siete dias del mes de mayo». El hecho de que el Doc. 2 haga alusión a las "representaçiones" y el Doc. 3 a la "representaçión» en el día del Santísimo Sacramento, así como el que las personas que recibieron el dinero fueran dos individuos diferentes - Mateo Fernández y Pedro Muñoz-, nos lleva a pensar que, en este año de 1571, hubo más de una representación con motivo de la misma festividad.

En la villa de Albacete también fue el Concejo Municipal el encargado de subvencionar las representaciones del Corpus, pero parece ser que no en su totalidad: "para ayuda de costa de una comedia» (Doc. 1), "para ayudar al gasto quel haze de las representaçiones» (Doc. 2), "para ayuda de costas de la representaçion" (Doc. 3); posiblemente fuesen las cofradias las encargadas de pagar el resto, ya que también lo eran de organizar los actos.

Nos ofrecen datos claros de la parte crematística: «dos ducados» (Doc. 1), «mil maravedis» (Doc. 2), "veinte y dos reales» (Doc. 3). Precios muy baratos si los comparamos con los «90 ducados por dos carros, uno de ellos escenificaba una obra sobre la Soberbia y caída de Lucifer y el otro sobre Nabucodonosor y el horno" que, en 1561, se abonaron en Sevilla a Juan

1 J. P. W. Crawford, Spanish drama before Lope de Vega. Philadelphia, University of Pennsylvania Press, 1937, p. 146.

2 N. D. Shergold, A History of the Spanish stage from Medieval times until the end of the Seventeeth Century. Oxford, University Press, 1967, p. 109. 
de Figueroa, clérico presbítero ${ }^{3}$. Esta diferencia de precio podemos interpretarla como que en Albacete únicamente se pagaron gastos que incluían el atrezzo - tablado o carro- pero no el trabajo de los actores. Todo ello nos llevaría a pensar que los actores que aquí representaron no eran profesionales, y por ello no cobraron. Lo pagado en Albacete se aproxima más a lo que se pagó en 1536: "un ducado» "a unos que habian hecho una farsa en la iglesia la resurrección pasada» ${ }^{4}$, y a los 1.200 maravedís que, en 1503 , se pagaron a Lucas Fernández por el «abto de los Pastores». También se aleja mucho de los 70 ducados cobrados por Cosme de Oviedo en 1561 . Todo ello quizá sea motivado por la categoría de la ciudad y la escasa frecuencia de «funciones».

Nada sabemos de los actores, pero el hecho de que las personas, a las que se les encomendó la función, fuesen vecinas de la villa de Albacete nos sirve de apoyatura para pensar que los actores eran también personas de la localidad.

El lugar escénico bien pudo ser el exterior o el interior de la iglesia de San Juan Bautista, ya que las Actas Municipales hacen alusión a la colocación de andamios en la citada iglesia para la fiesta del Corpus.

Igualmente desconocemos la hora de las representaciones, asi como sus títulos y si fueron acompañadas de danzas y bailes.

Notemos que ninguno de nuestros documentos habla de auto, sí lo hacen de comedia y representación. En este punto, además de recordar la dificultad de delimitación entre los términos, no debemos olvidar que en el Manuscrito de 1590 a las piezas de carćter religioso se las llama «comedias" ${ }^{6}$.

Sirva lo que hasta aquí traemos para ampliar la panorámica general del teatro en España.

3 Opinión vertida por López Prudencio y recogida por Manuel SiTo ALBA: «El teatro en el siglo XVI (desde finales de la Edad Media a comienzos del siglo XVII), en José María DíEZ Borque (ed.): Historia del Teatro en España. I. Edad Media. Siglo XVI. Siglo XVII. Madrid, Taurus, 1984, p. 383.

- Manuel Sito Alba: «El teatro en el siglo XVI (desde finales de la Edad Media a comienzos del siglo XVII), en José María Díez Borque (ed.): Historia del Teatro en España. I. Edad Media. Siglo XVI. Siglo XVII. Madrid, Taurus, 1984, p. 382.

3 SHERGOLD, op. cit., p. 85

- José Maria Diez Borque: Los Géneros Dramáticos en el siglo XVI (El teatro hasta Lope de Vega). Madrid, Taurus, 1987, p. 101. 


\section{DOCUMENTO 1}

A.H.P. Albacete. Sección Municipios, Albacete, legajo 453.

Juan de Olivares mayordomo del Concejo desta villa de Albaçete que de los/ propios della dad y pagad a Bernard Rios, veçino desta villa/ dos ducados que se le mandan librar para ayuda de costa de/ una comedia que haze por el dia del santisimo sacramento/ y tomad del su carta de pago que con ella y este libra/miento se os tomaran en quenta. Fecho Albaçete/ en honze de junio de myl e quinientos y sesenta e ocho años/. Mandose hacer este libramiento por los señores Bartolome del Monte(?)/ y el liçençiado Alarcon, rregidores, o quien se cometio por/ el ayuntamiento/

Françisco Gonzalez/ Anton Sanchez de Munera/ El liçençiado Alarcon/ Bartolome del Monte(?)/ Pablo Fernandez/ Françisco de Cañavate Çebrian/ Por mandado/ Bartolome de Munera/ 200 maravedis/

\section{(Al dorso)}

Digo yo Bernardo Rios ques verdad aver resebido del señor Juan de Olivares dos ducados para los gastos/ de la representacion del dia del Señor deste año mil y quinientos y sesenta y ocho años/y por ques verdad yze la presente carta de pago escrita de mi mano/ y firmada de mi nombre, fecha a catorze de junio año de mil y quiniehtos sesenta 68(?)/

Bernardo Rios/ Passado/ 53/ Dos ducados/Pagada/

\section{DOCUMENTO 2}

A.H.P. Albacete. Sección Municipios, Albacete, legajo 453.

Françisco Garçia Fernandez de Cordova nuestro mayordomo de los maravedis de vuestro car/go dad e pagad a Mateo Fernandez maestro de capilla de la yglesia mayor/desta villa mil maravedis que se le dan para ayudar al gasto quel haze de las/representaçiones que a de hazer el dia del Santisimo Sacra/mento desde presente anno e tomad su carta de pago que con ellos/y este mandamos se os rreciban en cuenta. Fecho en Alvaçete en dies/y siete dias del mes de mayo de mil y quinientos y setenta e un anos/Juan Martyn Garçon/ Françisco Alonso de Otar (?)/ Pablo Hernandez/Françisco de Cannabate Çebrian/ Myguel Soriano/ Françisco de Cantos/Por su mandado Jeronimo de Arboleda escrivano/ 


\section{(Al dorso)}

Rresçebi yo Mateo Fernandez, maestro de capilla de Garci Fernandez de Cordova, mayordomo del con/çejo los mil maravedis en esta otra parte contenidos y lo firmo de mi nombre/

Mateo Fernandez maestro de capilla/ Passado/

\section{DOCUMENTO 3}

A.H.P. Albacete. Sección Municipios, Albacete, legajo 453.

Françisco Garçia de Cordova mayordomo del concejo desta villa de Alvaçe/te dad la paga a Pero Muñoz estante en esta villa de Alvaçete veinte/ y dos reales que se le dan para ayuda de costas de la represen/taçion que a de hazer el dia del Santisimo Sacramento deste/ presente ano e tomad su carta de pago que con ellos y este man/damos se os rresçiban en cuenta. Fecho en Alvaçete en dies y siete/ dias del mes de mayo de mil y quinientos y setenta e un anos/

Juan Martyn Garçon/ Françisco Alonso de Otar (?)/ Pablo Hernandez/ Françisco de Cannabate Çebrian/ Myguel Soriano/ Françisco de Cantos/ Por su mandado Jeronimo de Arboleda escrivano/

\section{(Al dorso)}

Rresçebi yo Pedro Muñoz los maravedis contenidos en este libramento de esta otra/ parte contenidos de Garçi Fernandez de Cordoua y por la verdad lo firmo de/ mi nombre, fecho en la villa de Alvaçete a 17 de mayo de mil quinientos e setenta e un años/

Pedro Muñoz/ Passado/ 